\title{
Beaver activity increases habitat complexity and spatial partitioning by steelhead trout
}

\begin{tabular}{|r|l|}
\hline Journal: & Canadian Journal of Fisheries and Aquatic Sciences \\
\hline Manuscript ID & cjfas-2018-0171.R1 \\
\hline Manuscript Type: & Article \\
\hline Author: & 20 -Jul-2018 \\
\hline Complete List of Authors: & $\begin{array}{l}\text { Wathen, Gus; Eco Logical Research Inc. } \\
\text { Allgeier, Jacob; University of Michigan, Department of Ecology and } \\
\text { Evolutionary Biology } \\
\text { Bouwes, Nicolaas; EcoLogical Research, Inc., ; Utah State University, } \\
\text { Watershed Sciences } \\
\text { Pollock, Michael; Northwest Fisheries Science Center } \\
\text { Schindler, Daniel; University of Washington, School of Aquatic and } \\
\text { Fishery Sciences } \\
\text { Jordan, Christopher; National Marine Fisheries Service - NOAA, }\end{array}$ \\
\hline Keyword: & $\begin{array}{l}\text { BEHAVIOR < General, HABITAT < General, STREAMS < } \\
\text { Environment/Habitat, MOVEMENT < General, RESTORATION < General }\end{array}$ \\
\hline $\begin{array}{r}\text { Is the invited manuscript for } \\
\text { consideration in a Special } \\
\text { Issue? : }\end{array}$ & Not applicable (regular submission) \\
\hline &
\end{tabular}

\section{SCHOLARONE ${ }^{\text {M }}$ \\ Manuscripts}




\section{Beaver activity increases habitat complexity and spatial partitioning by steelhead trout}

3 Gus Wathen ${ }^{*}{ }^{+}$, Jacob E. Allgeier ${ }^{b+}$, Nicolaas Bouwes ${ }^{a}$, Michael M. Pollock ${ }^{\mathrm{c}}$, Daniel E.

$4 \quad$ Schindler ${ }^{\mathrm{d}}$ and Chris E. Jordan ${ }^{\mathrm{c}}$

$5 \quad$ a Eco Logical Research Inc., Providence, USA

$6 \quad{ }^{\mathrm{b}}$ Department of Ecology and Evolutionary Biology, University of Michigan, Ann Arbor, USA

7 c Northwest Fisheries Science Center, National Marine Fisheries Service, NOAA, Seattle, USA

8 d School of Aquatic and Fisheries Sciences, University of Washington, Seattle, USA

$9+$ equal contribution

10 * Corresponding author: gus.wathen@ecologicalresearch.net

11 


\section{Abstract}

13 Freshwater habitat restoration is a major conservation objective, motivating efforts to

14 restore habitat complexity and quality for fishes. Restoration based on the engineering activities

15 of beavers (Castor canadensis) increases fish habitat complexity, but how this affects fish habitat

16 use and movement behaviours is not well known. We used a network of passive integrated

17 transponder (PIT) antennas to quantify small-scale movement and microhabitat use of 175

18 individual juvenile steelhead (Oncorhynchus mykiss) in a stream channel with a complex

19 bathymetric profile resulting from a beaver impoundment, and a simplified channel devoid of

20 beaver activity. Our results show that juvenile steelhead exploit microhabitat heterogeneity by

21 employing a range of behaviours that maximizes available habitat via spatial and temporal

22 partitioning among individuals. These results suggest spatial resource partitioning as a potential

23 mechanism for the previously established positive correlations between steelhead density,

24 survival, and production with beaver-based restoration within the study watershed. More

25 broadly, our findings provide insight as to how populations can exploit habitat complexity

26 through spatial partitioning that can be informative for planning restoration and management

27 actions. 


\section{Introduction}

Habitat degradation is one of the principal threats to freshwater populations worldwide

(Dudgeon et al. 2005), with over a third of the rivers in the United States designated as impaired

31 (U.S Environmental Protection Agency 2000). Such concerns have precipitated the spending of over \$1 billion annually on river restoration efforts throughout the US (Bernhardt et al. 2005). A primary objective of restoration is enhancing habitat complexity, but efforts are often undertaken with a lack of understanding of underlying processes that make more complex habitats more suitable for freshwater fish populations (Palmer et al. 2010).

Previous research has shown habitat complexity to be an important driver of resource diversity for wildlife (Kovalenko et al. 2011). These ideas are rooted in theory whereby

38 increased population-level dietary niche diversity (the diversity of resources that the population feeds on) promotes increased resource partitioning among individuals (Roughgarden 1972;

Bolnick et al. 2007). In turn, the reduced competition for resources associated with resource partitioning can lead to increased carrying capacity (Harrison et al. 2017) and population

42 resilience to environmental stochasticity (Wolf and Weissing 2012). Resource partitioning among individuals has been linked directly to habitat complexity. For example, intra-population resource partitioning has been shown to increase along a continuum of increased habitat 45 complexity in mangrove ecosystems (for gray snapper (Lutjanus griseus; Layman et al. 2007) and tropical montane forests (for vampire bats (Desmodus rotundus; Layman et al. 2007;

47 Streicker and Allgeier 2016). Yet, a mechanistic link between improved habitat and increased resource partitioning is still missing, in part because of our lack of understanding of the influence of habitat complexity on how individuals differentially utilize the habitat, i.e., spatial 50 partitioning. 
The promotion of dam building by beavers (Castor canadensis), either naturally or

52 through building of beaver dam analogs (BDAs) is being used as a tool to restore streams and

53 improve fish habitat by reversing the negative effects of channel incision via sediment

54 aggradation and floodplain re-connection (Pollock et al. 2014; Bouwes et al. 2016). Recently,

55 Bouwes et al. (2016), demonstrated that juvenile steelhead (anadromous Oncorhynchus mykiss)

56 abundance, survival, and production increased dramatically following the introduction of BDAs

57 and a subsequent increase in dam building activity by beaver, relative to a control watershed.

58 They hypothesized that the increase in these responses were, in part, due to the increase in

59 habitat complexity in beaver dam complexes. However, the manner in which the juvenile

60 steelhead behaviour changed to affect how they use microhabitats following an increase in dam

61 complexes is unknown.

A growing body of research is revealing the importance of complex habitat use patterns

63 in juvenile steelhead and other salmonids at various temporal periods (see Gowan et al. 1994).

64 Steelhead are known to prefer shallow slow moving water as fry, and shift towards deeper

65 habitats with greater velocities as they age (Everest and Chapman 1972). However, juvenile

66 salmonids often display diel shifts in habitat use in response to predatory pressures (Metcalfe et

67 al. 1999), for energy sequestration (Reeves et al. 2009; Sloat et al. 2013), and for utilizing

68 thermal refugia (Brewitt and Danner 2014). Further, diverse movement behaviours exist within

69 populations, which may indicate alternate survival strategies (Steingrímsson and Grant 2003;

70 Myrvold and Kennedy 2016). These movement behaviours are important for conservation

71 because they may provide clues about survivorship, but research to date has been inconclusive as

72 to potential mechanisms. We aim to develop a better understanding of habitat use that can inform 
73 future restoration actions by gaining detailed information on small-scale movement patterns of a

74 threatened cold-water species, during a survival bottleneck (i.e., warm water, low discharge).

Here we test the hypothesis that spatial partitioning among individuals will increase with

76 increased habitat heterogeneity. We do so by monitoring the movement and habitat use

77 behaviour of individuals within a threatened population of juvenile steelhead for a week in two

78 study reaches within a stream; one that is impounded by a beaver dam with high diversity in

79 habitat characteristics, and the other in a simplified channel with a homogeneous bathymetric

80 profile. We conducted this study during mid-summer, where high water temperatures and

81 decreased discharge create a potential survival bottleneck for juvenile steelhead in our study

82 system. Specifically, we were interested in two questions:

1) How do beaver complexes affect habitat use by juvenile steelhead with respect to microhabitat selectivity and time of day?

2) Does habitat heterogeneity increase spatial partitioning by affecting movement and habitat use behaviours?

We hypothesized that fish "select" for certain microhabitats within study reaches and that this selection is driven by the availability of favorable water depths and velocities. Further, we expect increased spatial partitioning by individuals in the beaver dam complex, resulting from increased habitat heterogeneity. 
USGS Gauge 14046778, 2006-2016). Stream gradient in the lower $32 \mathrm{~km}$ of Bridge Creek

96

97

98

99

100

101

102

103

104

105

106

107

108

109

110

111

112

113

114

115

116

117

ranges from $1 \%$ to $3 \%$, with active channel widths between $4 \mathrm{~m}$ and $8 \mathrm{~m}$. Water temperatures in

Bridge Creek often approach the thermal survival threshold for its steelhead population $\left(29^{\circ} \mathrm{C}\right.$;

Rodnick et al. 2004) during mid-summer months (Weber et al. 2017). The fish community of

Bridge Creek is dominated by steelhead, dace (Rhinichthys spp.), and suckers (Catostomus spp.).

Common potential predators of the juvenile steelhead are great blue heron (Ardea herodias), belted kingfisher (Megaceryle alcyon), garter snakes (Thamnophis elegans) and occasionally

river otters (Lontra canadensis). Riparian vegetation is primarily composed of willow species

(Salix spp.), with dogwood (Cornus sericea), alder (Alnus spp.), and cottonwood (Populus spp.)

present in patches.

The lower $32 \mathrm{~km}$ of Bridge Creek is part of a long-term ecosystem experiment testing

how beaver dam persistence and abundance in a highly degraded, incised stream channel affects

the freshwater production of steelhead (Bouwes et al. 2016). This experiment involves

promoting beaver activity and building artificial beaver dams in incised plane-bed channels

characterized by homogenous depth and velocity profiles, with the goal to stimulate pool

creation, channel aggradation and floodplain reconnection (Pollock et al. 2012). Our objective

was to document spatial utilization behaviors of juvenile steelhead in a stream channel with high

depth complexity $(\mathrm{CV}$ of depth $=0.8)$ resulting from beaver activity, and a plane-bed channel

with relatively homogeneous depths $(\mathrm{CV}$ of depth $=0.34)$ reflective of degraded reaches on

Bridge Creek. For this study, we define habitat heterogeneity as variation in the bathymetric

profile of the stream channel, which also influences water velocity and fish cover.

We used a network of PIT antennas to quantify juvenile steelhead microhabitat use and movement in an area around an active beaver impoundment (henceforth beaver complex), and a

[6] 
118 plane-bed run void of proximal beaver activity (henceforth, run). We deployed 11 antennas in

119 the beaver complex, and 10 antennas in the run. We placed antennas systematically $(>1 \mathrm{~m}$ apart

120 to avoid antenna cross talk), in an attempt to cover the broad ranges of depths, velocities,

121 substrate, and other types of fish cover at each site (i.e., microhabitats), while maintaining a

122 consistent spacing. Each antenna operates at a frequency of $134 \mathrm{kHz}$ and has measured vertical

123 detection range of $35-40 \mathrm{~cm}$ for the PIT tags $(12.5 \mathrm{~mm}, 134.2 \mathrm{kHz}$, full duplex; Biomark HPT12,

124 Boise, Idaho $)$ used in this study. We constructed antenna housing $(66 \mathrm{~cm} \times 66 \mathrm{~cm}$; area $=0.44$

$125 \mathrm{~m}^{2}$ ) out of PVC (polyvinyl chloride; $\mathrm{OD}=2.6 \mathrm{~cm}$ ). Antenna housing diameter was kept to a

126 minimum to avoid adding a bed roughness component to the stream channel that could influence

127 fish behavior. We equipped each antenna with OnsetC temperature loggers (UTBI-001, U22-

128 001) to record hourly temperatures. Antennas were connected to a multiplexing PIT-tag reader

129 by cable lengths of $15 \mathrm{~m}$. We used custom multiplexing modules paired with RM310 PIT tag

130 readers (Allflex, www.allflexusa.com) to activate antennas for 0.25 seconds per cycle. The

131 multiplexer unit was powered by a $6 \mathrm{~V}(200 \mathrm{Ah})$ rechargeable absorbent glass mat battery pack,

132 which combined with a solar panel, provided continuous power. This system enables logging up

133 to 100,000 time-stamped detections per day with an onboard data logger. To reduce the number

134 of repetitive events, a data repeated filter precluded the repeat reading of the same tag code, at

135 the same antenna, within each 1-minute period. Therefore, we refer to all detections as "minutes"

136 at which fish were detected by an antenna. For this study, we define a microhabitat as equal to

137 the area that our antennas represent $\left(0.44 \mathrm{~m}^{2}\right)$.

The beaver complex and run study reaches were located at river kilometers 26 and 17 , 
141 The run study reach area was $17 \mathrm{~m}$ long with a surface area of $51.2 \mathrm{~m}^{2}$ and located in the middle

142 of a $57.7 \mathrm{~m}$ plane-bed channel feature. The $20 \mathrm{~m}$ beaver complex consisted of lotic conditions

143 flowing into a lentic channel feature resulting from a beaver impoundment, and a subsequent

144 plunge pool below the impoundment. The surface area of the complex was $89.3 \mathrm{~m}^{2}$ (Fig. 1). We

145 conducted a topographic survey of stream channel morphology in both monitoring sites at

146 baseflow conditions in November, 2015 (CHaMP 2014). We used digital elevation models

147 (DEMs) generated from topographic surveys to run hydraulic models (Wheaton et al. 2017) that

148 utilize bed roughness and a porous plate structure at the beaver impoundment to predict average

149 water column velocity and obtain depths of our study areas at a grain size equal to that of

150 antenna area. We georeferenced antenna locations and identified the overlapping model

151 predicted depth and velocity microhabitats as "sampled", while other microhabitats were deemed

152 "available".

153 We used PIT tags to identify individual steelhead that used the study reaches. PIT tags

154 are advantageous because they are inexpensive, have no battery, and can be used in small fish (>

$15570 \mathrm{~mm})$. However, they are susceptible to tag collision, the size limitation precludes age 0

156 steelhead, and have a limited detection range. Fish were tagged as part of tri-annual surveys that

157 utilize electrofishing catch data of juvenile steelhead to estimate abundance using mark-recapture

158 models (Bouwes et al. 2016; Wathen et al. 2017). All capture and tagging efforts were

159 completed by $6 / 26 / 2015$, allowing for a minimum of six days for re-acclimation before recording

160 of habitat use and movement patterns. We placed antennas and began data collection in study

161 reaches on 6/30/15, at baseflow conditions. We truncated our data set to include records from 7

162 full days (7/1/15 6:00 am through 7/7/15 5:59 am) to accommodate a 24-hour acclimation

163 period. We chose to limit our data set to a week's time because we were interested in 
164 understanding if small-scale movement may help us understand how juvenile steelhead navigate

165 Bridge Creek's most stressful conditions (high temperatures, low discharge) on a daily basis. We 166 were constrained by the logistical challenges of maintaining the extensive array over extended 167 periods of time. During observations, there was no presence by our research team in or around 168 the study reaches to avoid a fish behavioral response to human disturbance.

\section{Data analysis}

\section{Question 1: Aggregate Habitat Selection}

We were specifically interested in testing if fish "selected" for certain microhabitats

172 defined by depth and velocity at separate times of the day. To answer this, we tested the

173 probability that fish occupied the microhabitats where we placed our antenna, relative to the

174 availability of all potential microhabitats within each study reach. The beaver complex and the

175 run were divided into 201 and 116 microhabitat cells using hydraulic model outputs to

176 characterize habitat, herein referred to as "available" microhabitats, representing all the possible

177 areas a fish could occupy within a given reach. Antenna locations were non-randomly chosen for

178 each study reach and accounted for $5.4 \%$ and $8.5 \%$ of the microhabitats respectively - herein

179 referred to as "sampled" microhabitats. To determine if fish preferred the sampled versus the

180 available microhabitats, we estimated the depth and velocities for each available microhabitat

181 cell. We then compared the distribution of microhabitat depths and velocities that were used by

182 the fish (frequency that fish used one of the sampled microhabitats) to null distributions of what

183 would be expected from random use of all available microhabitats. Specifically, to generate this

184 null distribution we randomly sampled depths and velocities from all available microhabitats (n

$185=564480$ for the beaver complex and $n=315360$ for the run; these values represent the total

186 potential time in minutes that all observed fish could have been recorded within a given 
"sampled" microhabitat over a seven-day period). We then removed all depths and velocities from this null distribution that were different from the sampled microhabitats - creating a null distribution that describes the probability that fish "chose" the microhabitat represented by our antennas by chance. We then compared these null distributions to the observed distributions using a T-test and a Kolmogorov Smirnov test (herein KS-test; $\alpha<0.1$ for both tests).

We used a generalized linear model to test if microhabitat selection, i.e., the number of detection minutes per antennae (log transformed to reduce skew), was predicted by either depth or velocity. To explicitly test for differences between the run and beaver complex, we used the study reach as an interaction term for both velocity and depth. We also included variables for substrate and cover in initial models, but they contributed little to the predictive power of the model, and thus were not included in our final models.

To test how fish changed microhabitat use over the course of the day, we first split each day into four time bins (diel periods): morning (6:00 am-11:59 am), afternoon (12:00 pm - 5:59 pm), evening (6:00 pm - 11:59 pm), and night (12:00 am - 5:59 am). For each diel period we counted the number of unique fish detections at each of the antenna. For visualization and qualitative purposes, we plotted the average number of unique fish detected per day at each antenna during four diel periods. We then ranked antennas, from most visited (rank $=1)$ to least visited, as a measure of "preference". We quantified the magnitude of change in preference rank each antenna had over different diel periods across all days as a measure of the difference between the rank at that period and the average rank of the antenna across time, e.g., rank $_{\text {average }}-$ rank $_{\text {morning. }}$ As a measure of this variation we calculated the coefficient of variation $(\mathrm{CV})$ of the changes in antenna rank across time for each antenna and used a T-tests and KS-test to quantify differences in the mean of CVs and their relative distribution between the two study reaches. In 
210 doing so we could assess the degree to which fish changed their utilization of antennas over the 211 course of the day.

\section{Question 2: Individual Behaviour}

We tested whether fish occupying a heterogeneous habitat partition the spatial niche in a

214 more discrete manner than those in a more homogenous environment. To do so, we quantified 215 the degree of spatial partitioning (i.e., specialization in movement and habitat use behaviors 216 described below) of individuals residing in the run and beaver complex reaches. To remove fish 217 with little habitat use information from behavioral analyses, we imposed a residency criterion 218 where fish had to be observed in two or more days, and at least 20 times for inclusion. There 219 were 65 fish in the beaver complex, and 19 fish in the run that met the residency criterion. antenna and the directionality of use (i.e., the antennas fish moved to and from) at unique oneminute intervals. Fish movement was characterized according to activity or boldness. Activity describes the number of transitions made between discrete antennas, as well as the use of these

224 antennas; i.e., multiple detections of the same fish at the same antenna. Boldness describes how a 225 fish is to travel further between detections (potentially more risky behavior) and is quantified as 226 the number of transitions multiplied by the physical distance (meters) between antennas. For 227 each study reach, we quantified the proportion of antennas utilized by each fish (the number of 228 antenna used relative to the number available), as a measure of home range size.

229 We calculated the degree of spatial partitioning (i.e., specialization in movement behavior 230 as a measure of the degree in overlap among individuals) by modifying analyses of individual-

231 level dietary specialization from Bolnick et al. (2002). Specifically, we calculated the PS 232 (specialization measure) per individual: 


$$
\mathrm{PS}_{i}=1-0.5 * \sum_{j}\left|P_{i j}-Q_{j}\right|
$$

234

235

236

237

238

239

240

241

242

243

244

245

246

247

248

249

250

251

252

253

254

255

Where, $P$ is a proportional matrix (used by Bolnick et al. (2002) as an individual (row) by dietary item (column) matrix, here converted from the raw transition matrices for each fish creating an individual by antenna matrix), $P_{i j}$ is the proportion (number of discrete transitions / total number of transitions) of the $j$ th antenna that the individual $i$ used, and $Q_{j}$ is the proportion of the $j$ th antenna used by the entire population (Bolnick et al. 2002). $\mathrm{PS}_{i}$ is a value from $0-1$ where the lower the value the smaller amount of spatial overlap that individual has with others (i.e., they are more specialized in their movement). This metric is typically used in the context of a dietary niche (Bolnick et al. 2003; 2007), but can be applied for additional measures of niche space (Allgeier et al. 2017), as well as spatial partitioning as applied herein. This metric was calculated for the activity (the amount of movement between antennas as well as the use of these antennas) and boldness (distance of movement; i.e., the number of transitions multiplied by the physical distance) for each individual. Both T-test and KS-tests were used to compare the means and spread of the distribution of individual $\mathrm{PS}_{\mathrm{i}}$ values between study reaches. Because there were only 19 individuals that met the residency criteria in the run, bootstrapping was used to resample 19 individuals from the beaver complex to make equal sample size comparisons - this process was reiterated 100 times per statistical test, the average $p$-value is reported with significance at $\alpha<0.1$. We included results from both original and bootstrapped datasets for all comparisons.

To test if individual spatial partitioning (i.e., behaviors) changed throughout the day, we subdivided the day into the four diel periods mentioned previously and quantified the proportion of antenna locations used by individual fish, and the degree of specialization of activity that occurred at each diel period. Again, a bootstrapping technique was used to resample 19 
256 individuals from the beaver complex to make equal sample size comparisons - this process was

257 reiterated 100 times per for which comparisons were made using T-tests and KS-tests.

258 Results

From abundance surveys, we estimated the densities of juvenile steelhead to be 3.2 fish 260 per linear meter in the monitoring site with beaver activity, and 1.3 fish per linear meter in the 261 site containing the run (Table 1). Over the seven days of observation we recorded 96 unique 262 individuals in the beaver complex and 79 individuals in the run. In the complex, $27 \%$ of 263 recorded fish were only present for 1-2 days; 22\% were recorded in 3-4 days; and 51\% were 264 recorded in 5-7 days. Conversely, most fish (50\%) in the run were recorded for 1-2 days; 26\% 265 were recorded 3-4 days; and 24\% were recorded 5-7 days. The average number of unique fish 266 detected at individual antennas was 42.8 in the beaver complex, and 32.1 in the run. The highest 267 proportion of time accounted for by any one individual was $22.3 \%$ in the beaver complex, and $29.7 \%$ in the run. Water temperature averaged $19.7^{\circ} \mathrm{c}\left(\right.$ range $\left.=15.1-25.9^{\circ} \mathrm{c} ; \mathrm{CV}=0.028\right)$ in the beaver complex and $22.2^{\circ} \mathrm{c}$ in the run (range $\left.=17.6-27.7^{\circ} \mathrm{c} ; \mathrm{CV}=0.007\right)$.

\section{Question 1: Aggregate Habitat Selection}

272 site selectivity in both study reaches. We found that fish "selected" for certain microhabitats and 273 this selection was driven by attributes of the habitat (i.e., depth and velocity) and time of day 274 (Fig. 2; Fig. 3). First, we found that fish occupancy of the "sampled" microhabitats (as defined 275 by the depth and water velocity at a given antenna) significantly differed from random site occupancy (T-test and KS-test $p$-value $<0.001)$. We found that distributions of microhabitats

277 used based on depth in both study reaches tended to be skewed right, indicating greater 278 selectivity for deeper locations (Fig. S1). Distributions of microhabitats used based on velocity 
279 were more similar in shape to the available microhabitats in both study reaches, but slightly 280 skewed left suggesting preference for slower moving water.

We extended this analysis using a linear model to directly test for the importance of depth

282 and velocity for microhabitat selection in both study reaches. There was a significant effect of

283 both depth (positive) and velocity (negative) for microhabitat selection by fish, but this

284 relationship differed among study reaches, i.e., there was a significant interaction between depth

285 and study reach, and velocity and study reach ( $p$-value $<0.001$; Table 2$)$. These factors explained

$286 \sim 60 \%$ of the variation in the data and were better predictors for selection in the run than in the 287 beaver complex.

Differences were visually apparent in the preference of certain microhabitats throughout the day by the two populations (Fig. 3). For example, antennas five and eight were always the most visited antennas in the run, regardless of time of day - these antennas were characterized by

291 deeper water and the presence of velocity sheer zones created by large substrate; however,

292 antenna preference seemed to change substantially through diel periods in the beaver complex.

293 Differences in CV values per antenna preference rank were apparent between the two reaches;

294 though only marginally significant $(p$-value $=0.1)$. The mean antenna CV in the beaver complex 295 was 0.34 , with a range of $0-0.97$ (antennas eleven and five, respectively). Mean antenna CV in 296 the run was 0.19 with a range of $0.09-0.31$ (antennas nine and seven, respectively; Fig. 4). The 297 trend toward higher CVs in the beaver complex suggests that individuals tended to shift 298 preference for a given antenna more over the course of the day in the beaver complex than the 299 run. 


\section{Question 2: Individual Behaviour}

In the run, $24 \%$ of unique individuals met the residency criteria for inclusion in behavioral analyses, opposed to $68 \%$ of individuals detected in the beaver complex (Table 1), suggesting that most of the fish in the beaver complex spent a good deal of time in that habitat feature, while many fewer fish ended up spending significant time in the run. No difference was found between the beaver complex and the run with respect to the proportion of antennas individuals used with the bootstrap approach (Fig. 5); however, differences were significant ( $p=$ 0.1) when making comparisons with uneven sample sizes, i.e., the beaver complex had more residents. Significant differences were found in individual specialization metrics between the two study reaches for both activity (mean $p=0.02$, spread $p=<0.01$ ) and boldness (mean $p=<0.01$, spread $p=0.01$ ), with the beaver pond individuals displaying less spatial overlap (i.e., higher levels of spatial partitioning) in both regards (Fig. 5). This means that individual fish in the beaver complex displayed more unique behaviors (relative to the run) in terms of both what antennas they moved to and the distances they traveled across the reach.

The proportion of antennas used by individuals and their degree of spatial overlap was highly variable throughout the four diel time blocks (Fig. 6). Individuals in the beaver complex used a large proportion of the sampled microhabitats in the morning (not significant when applying the more conservative bootstrap), but a smaller proportion of sampled microhabitats in the afternoon and night time. Individuals were more specialized (higher degree of spatial partitioning) in the beaver complex only in the afternoon (Fig. 6).

\section{Discussion}

The structure of a habitat influences fish population productivity (Van Horne 1983), but the mechanisms by which this occurs are not well known. Understanding how individuals that 
323 share physical space modify their behaviour in relation to the complexity of their habitat may

324 offer insight into how individuals partition resources and the ecological interactions of a species

325 (Bolnick et al. 2002; White et al. 2014). Previous research in our study system (the Bridge Creek

326 watershed) demonstrated that beaver-based restoration increased habitat complexity, density, and

327 survival of juvenile steelhead (Bouwes et al. 2016). More broadly, beaver activity and beaver

328 dam analogues are being promoted as a potential restoration tool to remediate channel incision

329 (Pollock et al. 2014) and increase habitat complexity for the benefit of fish populations (Bouwes

330 et al. 2016; Dauwalter and Walrath 2017). Our research provides important new insights into the

331 mechanisms that may lead to enhance population productivity. We showed that improved habitat

332 quality (increased heterogeneity due to beavers) enhances the degree to which individuals

333 partition the physical space of the habitat, with implications for improved resource use efficiency

334 and population productivity (Kovalenko et al. 2011).

More juvenile steelhead used the beaver complex for longer durations, compared to the run. From our fish capture surveys, we know that the density of juvenile steelhead was almost

337 three times higher in the site impacted by beaver activity and, on average, these fish spent longer amounts of time within this habitat than in the more homogenous run. Our findings are consistent with other studies documenting increased biomass of juvenile anadromous salmonids in beaver

340 impacted tributaries whereby the presence of beavers increased habitat heterogeneity, providing 341 a larger range of growth opportunities for juvenile salmon (Malison et al. 2015). Beaver ponds 342 accommodate higher densities of some fish species (Bylak et al. 2014) because of the increased 343 microhabitat complexity associated with changes in depth and velocity (Dauwalter et al. 2014;

344 Bouwes et al. 2016). Depth and velocity have long been considered key drivers of habitat 345 selection in stream fishes (Everest and Chapman 1972), and their availably, in the form of 
346 suitable microhabitats for stream dwelling salmonids, can limit a system's carrying capacity of 347 those fish (Ayllón et al. 2012).

Habitat heterogeneity generates opportunities for stream fish to use a range of

microhabitats depending on daily needs (i.e., foraging, predator avoidance, energy conservation; (Schlosser 1991). We found that juvenile steelhead selected for greater depths and slower water velocities in both study reaches, but selection was stronger in the run (indicated by the importance of reach in the linear habitat use model; Table 1), indicating limited desirable depth and velocity conditions within that reach. Specifically, in the run the two deepest antennas were always the most selected for - regardless of the time of day, and the preference for other antenna differed little between periods of the day (Fig. 3; Fig. 4). In contrast, the time of day was important for antenna preference in the beaver complex (Fig. 3; Fig. 4). For example, the deepest portion of the pool (antenna five) was the most popular location when the sun was highest (i.e., morning, and afternoon), but it was almost devoid of fish during nights presumably as a response to the increased threat of diurnal avian predation (Metcalfe et al. 1999). Conversely, the tail-out of the plunge pool below the impoundment (antenna one; Fig. 1) was generally avoided during the day, but became the most selected for antenna at night, as many salmonids will make nocturnal moves to shallower areas away from cover (Jakober et al. 2000; Albrecht and Gotelli 2001; Reeves et al. 2009; Hines et al. 2017). Diel shifts in habitat use can occur due to crepuscular foraging (Bradford and Higgins 2001); predator avoidance (Metcalfe et al. 1999); minimizing respiration at high water temperatures (Sloat et al. 2013); and reducing swimming cost at night (Reeves et al. 2009). In the run, the limited availability of desirable habitat dictated habitat use - allowing for only slight habitat use variation in response to diverse daily needs of fish. Whereas in the beaver complex, the shrinking proportion of antennas 
used in the afternoon and night indicate there were very specific and desirable places to be during those discrete diel periods (Fig. 6). Therefore, we can conclude that availability of quality habitat constrains the degree to which fish can vary their daily habitat preference and that habitat heterogeneity allows variation in habitat selection over the diel cycle.

Understanding how individuals partition an ecological niche has a long history in ecology (Roughgarden 1972), and has been a central tool used to understand competition and coexistence among individuals - with the central idea being that higher rates of niche partitioning can reduce competition and enhance coexistence (Huston 1994). Our study showed that within the beaver complex, individual fish established more distinctive patterns of spatial use of microhabitats than in the run. This pattern is reflected in increased specialization in activity and boldness behaviors, and variation in diel movement patterns of individuals in the beaver complex relative to those in the run where individuals showed less variation in their habitat selection strategies. In the run, individuals either established use patterns at the two deepest antennas, or used other habitat in seemingly random ways, presumably as if they are searching for quality microhabitat (Fig. 2;

Fig. 4). In the beaver complex, individuals display more specialized habitat use and movement patterns that changed through the day, presumably allowing individuals to fulfil daily needs (i.e., foraging, digestion, predator avoidance) in different physical space at different times. These findings identify increased spatial partitioning (i.e., specialized movement behaviour) as a potential mechanism that allows the coexistence of increased abundance of steelhead in habitats altered by beavers.

In addition to physical alterations, beaver impoundments can change the structure of the invertebrate community within a stream by replacing the lotic species with a lentic community (McDowell and Naiman 1986), thereby diversifying the potential prey base for fishes, with 
392 implications for increased numbers of population-level dietary niches (Tinker et al. 2008). The

393 movement specialization we observed within the beaver complex could represent segregation of

394 foraging behaviours such as drift foraging for lotic invertebrates flowing into the complex and 395 pelagic foraging for lentic invertebrates within the complex. Such diversification is unlikely in 396 the run because consistently higher water velocities may exclude lotic prey items found in beaver 397 ponds (e.g., water boatmen and amphipods), making pelagic foraging behaviours ill-suited for 398 that habitat.

Interestingly, there appears to be no apparent cost in growth rates for highly mobile 400 juvenile steelhead compared to stationary individuals, indicating the potential importance of two 401 disparate movement behaviours as a viable means to expanding population-level resource base 402 and to reduce intra-specific competition for resources (Kahler et al. 2001; Steingrímsson and 403 Grant 2003; Myrvold and Kennedy 2016). Collectively, our findings in conjunction with 404 previous work suggests that the diversity in beaver complex movement behaviours could be a 405 manifestation of dietary niche expansion (Harrison et al. 2017). Further, juvenile steelhead have 406 shown strong diel movement capabilities to exploit thermal refuge (Brewitt and Danner 2014).

407 Beaver impoundments can contain an increased diversity of near-bed water temperatures (Weber 408 et al. 2017), which our study confirms, as variation in temperatures between antennas in the 409 beaver complex was four times that observed in the run. Diel utilization of thermal refuge may 410 also be a key to survival during thermally stressful periods often observed in our study 411 watershed. Grids of PIT antennas are increasingly being used to understand individual fish behavior 413 and habitat use at fine scales (Johnston and Bergeron 2009; Roy et al. 2013a; 2013b). The use of 414 this system helped us compile a unique and comprehensive dataset on 175 individual fish 
415 locations over a seven-day period. However, two aspects of our study represent important

416 caveats. First, the lack of replication at the site-level limits our ability to make generalizations of

417 how juvenile steelhead utilize beaver complexes versus runs because the structure of beaver

418 complexes are variable, and fish responses change as beaver complexes age (Bylak et al. 2014).

419 Second, our antenna setup provided incomplete spatial and temporal coverage of the habitats we

420 sampled. This was especially apparent at night in the beaver complex as many fish detected by

421 day, were not detected by night. This detection limitation was particularly apparent via visual

422 observations (G.W.) of fish occupying the beaver complex tail out at night that were not

423 otherwise detectable in our dataset due to the absence of antennas in that respective area.

Our study provides new insights in how habitat complexity can affect individual-level

425 behavioural traits of habitat utilization and specialization. This study adds to the growing body of

426 research highlighting the utility of understanding individual-level variation in ecological traits (in

427 our case, movement) for ecological processes. This study also provides further support to the

428 idea that habitat quality positively affects population viability - a presumed, but generally

429 untested expectation for restoration efforts. Future efforts to integrate individual-level movement

430 behaviour into a broader set of tools used to assess habitat restoration will likely improve future

431 restoration efforts.

\section{Acknowledgements}

433 Funding for this project was provided by NOAA -National Marine Fisheries Service and

434 the Bonneville Power Administration (project 2003-017) and an NSF Postdoctoral Fellowship in

435 Biology to J.E. Allgeier. The authors thank B. Jonasson, P. Mackinnon, and G. Brooks for their

436 technical assistance; N. Weber for his help with conceptualization; J. Wirtz and D. Baumer for 
437 their contribution in the field; E. Wall, C. Saunders, and P. McHugh for their analytical support; 438 and M. Liermann and two anonymous reviewers for guidance and manuscript suggestions.

439 References

440 Albrecht, M., and Gotelli, N.J. 2001. Spatial and temporal niche partitioning in grassland ants.

441 Oecologia 126(1): 134-141. doi:10.1007/s004420000494.

442 Allgeier, J.E., Adam, T.C., and Burkepile, D.E. 2017. The importance of individual and species443 level traits for trophic niches among herbivorous coral reef fishes. Proc. Biol. Sci. 284(1856). 444 doi:10.1098/rspb.2017.0307.

445 Ayllón, D., Almodóvar, A., Nicola, G.G., Parra, I., and Elvira, B. 2012. Modelling carrying 446 capacity dynamics for the conservation and management of territorial salmonids. Fish. Res. 134447 136: 95-103. doi:10.1016/j.fishres.2012.08.004.

448 Bennett, S., Pess, G., Bouwes, N., Roni, P., Bilby, R.E., Gallagher, S., Ruzycki, J., Buehrens, T., 449 Krueger, K., Ehinger, W., Anderson, J., Jordan, C., Bowersox, B., and Greene, C. 2016. Progress 450 and Challenges of Testing the Effectiveness of Stream Restoration in the Pacific Northwest 451 Using Intensively Monitored Watersheds. Fisheries 41(2): 92-103.

452 doi:10.1080/03632415.2015.1127805.

453 Bernhardt, E.S., Palmer, M.A., Allan, J.D., Alexander, G., Barnas, K., Brooks, S., Carr, J., 454 Clayton, S., Dahm, C., Follstad-Shah, J., Galat, D., Gloss, S., Goodwin, P., Hart, D., Hassett, B., 455 Jenkinson, R., Katz, S., Kondolf, G.M., Lake, P.S., Lave, R., Meyer, J.L., O'donnell, T.K., 456 Pagano, L., Powell, B., and Sudduth, E. 2005. Synthesizing U.S. river restoration efforts. Science 457 308(5722): 636-637. doi:10.1126/science.1109769. 
458 Bolnick, D.I., Yang, L.H., Fordyce, J.A., Davis, J.M., and Svanback, R. 2002. Measuring

459 Individual-Level Resource Specialization. Ecology 83(10): 2936. doi:10.2307/3072028.

460 Bolnick, D.I., Svanback, R., Fordyce, J.A., Yang, L.H., Davis, J.M., Hulsey, C.D., and Forister, 461 M.L. 2003. The ecology of individuals: incidence and implications of individual specialization. 462 Am. Nat. 161(1): 1-28. doi:10.1086/343878.

463 Bolnick, D.I., Svanback, R., Araújo, M.S., and Persson, L. 2007. Comparative support for the 464 niche variation hypothesis that more generalized populations also are more heterogeneous. Proc. 465 Natl. Acad. Sci. USA 104(24): 10075-10079. doi:10.1073/pnas.0703743104.

466 Bouwes, N., Weber, N., Jordan, C.E., Saunders, W.C., Tattam, I.A., Volk, C., Wheaton, J.M., 467 and Pollock, M.M. 2016. Ecosystem experiment reveals benefits of natural and simulated beaver 468 dams to a threatened population of steelhead (Oncorhynchus mykiss). Sci. Rep. 6(28581). 469 doi:10.1038/srep28581.

470 Bradford, M.J., and Higgins, P.S. 2001. Habitat-, season-, and size-specific variation in diel 471 activity patterns of juvenile chinook salmon (Oncorhynchus tshawytscha) and steelhead trout 472 (Oncorhynchus mykiss). Can. J. Fish. Aquat. Sci. 58(2): 365-374. doi:10.1139/cjfas-58-2-365.

473 Brewitt, K.S., and Danner, E.M. 2014. Spatio-temporal temperature variation influences 474 juvenile steelhead (Oncorhynchus mykiss) use of thermal refuges. Ecosphere 5(7): 92. 475 doi:10.1890/ES14-00036.1

476 Bylak, A., Kukuła, K., and Mitka, J. 2014. Beaver impact on stream fish life histories: the role of 477 landscape and local attributes. Can. J. Fish. Aquat. Sci. 71(11): 1603-1615. doi:10.1139/cjfas$478 \quad 2014-0105$. 
479 CHaMP. 2014. Scientific protocol for salmonid habitat surveys within the Columbia Habitat 480 Monitoring Program. Prepared by the Integrated Status and Effectiveness Monitoring Program 481 and published by Terraqua, Inc. Wauconda, WA.

482 Dauwalter, D.C., Wenger, S.J., and Gardner, P. 2014. The role of complexity in habitat use and 483 selection by stream fishes in a Snake River basin tributary. Trans. Am. Fish. Soc. 143(5): 1177484 1187. doi:10.1080/00028487.2014.920723.

485 Dauwalter, D.C., and Walrath, J.D. 2017. Beaver dams, streamflow complexity, and the 486 distribution of a rare minnow, Lepidomeda copei. Ecol. Freshw. Fish. 27(2): 606-616. 487 doi:10.1111/eff.12374.

488 Dudgeon, D., Arthington, A.H., Gessner, M.O., Kawabata, Z.-I., Knowler, D.J., Lévêque, C., 489 Naiman, R.J., Prieur-Richard, A.-H., Soto, D., Stiassny, M.L.J., and Sullivan, C.A. 2005. 490 Freshwater biodiversity: importance, threats, status and conservation challenges. Biol. Rev. 491 Cambridge Philos. Soc. 81(2): 163-182. doi:10.1017/S1464793105006950.

492 Everest, F.H., and Chapman, D.W. 1972. Habitat selection and spatial interaction by juvenile 493 chinook salmon and steelhead trout in two Idaho streams. J. Fish. Res. Board Can. 29(1): 91494 100. doi:10.1139/f72-012.

495 Gowan, C., M.K. Young, K.D. Fausch, and S.C. Riley. 1994. Restricted movement in resident 496 stream salmonids: a paradigm lost? Can. J. Fish. Aquat. Sci. 51 (11): 2626-2637. 497 doi:10.1139/f94-262. 
498 Harrison, P.M., Gutowsky, L.F.G., Martins, E.G., Ward, T.D., Patterson, D.A., Cooke, S.J., and 499 Power, M. 2017. Individual isotopic specializations predict subsequent inter-individual variation 500 in movement in a freshwater fish. Ecology 98(3): 608-615. doi:10.1002/ecy.1681.

501 Hines, D., Lierman, M., Seder, T., Cluer, B., Pess, G. and Schoenebeck, C. 2017. Diel shifts in 502 micro-habitat selection of steelhead and Coho salmon fry. North Am. J. Fish. Manage. 37(5): 503 989-998. doi: 10.1080/02755947.2017.1339648

504 Huston, M.A. 1994. Biological Diversity. Cambridge University Press, Cambridge, England.

505 Jakober, M.J., McMahon, T.E., and Thurow, R.F. 2000. Diel habitat partitioning by bull charr 506 and cutthroat trout during fall and winter in Rocky Mountain streams. Environ. Biol. Fishes 507 59(1): 79-89. doi:10.1023/a:1007699610247.

508 Johnston, P., and Bergeron, N.E. 2009. Comparison between stationary antenna grid and portable 509 antenna PIT systems for studying fish habitat use. Geomatica 63(4): 313-320.

510 Kahler, T.H., Roni, P., and Quinn, T.P. 2001. Summer movement and growth of juvenile 511 anadromous salmonids in small western Washington streams. Can. J. Fish. Aquat. Sci. 58(10): 512 1947-1956. doi:10.1139/cjfas-58-10-1947.

513 Kovalenko, K.E., Thomaz, S.M., and Warfe, D.M. 2011. Habitat complexity: approaches and 514 future directions. Hydrobiologia 685: 1-17. doi:10.1007/s10750-011-0974-z.

515 Layman, C.A., Quattrochi, J.P., Peyer, C.M., and Allgeier, J.E. 2007. Niche width collapse in a 516 resilient top predator following ecosystem fragmentation. Ecol. Lett. 10(10): 937-944. 517 doi:10.1111/j.1461-0248.2007.01087.x. 
518 Malison, R.L., Eby, L.A., and Stanford, J.A. 2015. Juvenile salmonid growth, survival, and 519 production in a large river floodplain modified by beavers (Castor canadensis). Can. J. Fish. 520 Aquat. Sci. 72(11): 1639-1651. doi:10.1139/cjfas-2015-0147.

521 McDowell, D.M., and Naiman, R.J. 1986. Structure and function of a benthic invertebrate stream 522 community as influenced by beaver (Castor canadensis). Oecologia 68(4): 481-489. 523 doi:10.1007/bf00378759.

524 Metcalfe, N.B., Fraser, N.H.C., and Burns, M.D. 1999. Food availability and the nocturnal vs. 525 diurnal foraging trade-off in juvenile salmon. J. Anim. Ecol. 68(2): 371-381. doi:10.1046/j.1365$526 \quad 2656.1999 .00289 . x$.

527 Myrvold, K.M., and Kennedy, B.P. 2016. Juvenile steelhead movements in relation to stream 528 habitat, population density, and body size: consequences for individual growth rates. Can. J. 529 Fish. Aquat. Sci. 73(10): 1520-1529. doi:10.1139/cjfas-2016-0007.

530 Palmer, M.A., Mennninger, H.L., and Bernhardt, E.S. 2010. River restoration, habitat 531 heterogeneity and biodiversity: a failure of theory or practice? Freshw. Biol. 55: 1-18. 532 doi:10.1111/j.1365-2427.2009.02372.x.

533 Pollock, M.M., Beechie, T.J., Wheaton, J.M., Jordan, C.E., Bouwes, N., Weber, N., and Volk, C. 534 2014. Using Beaver Dams to Restore Incised Stream Ecosystems. BioScience 64(4): 279-290. 535 doi:10.1093/biosci/biu036.

536 Reeves, G.H., Grunbaum, J.B., and Lang, D.W. 2009. Seasonal variation in diel behaviour and 537 habitat use by age 1+ Steelhead (Oncorhynchus mykiss) in Coast and Cascade Range streams in 538 Oregon, U.S.A. Environ. Biol. Fishes 87(2): 101-111. doi:10.1007/s10641-009-9569-1. 
539 Rodnick, K.J., Gamperl, A.K., Lizars, K.R., Bennett, M.T., Rausch, R.N., and Keeley, E.R.

540 2004. Thermal tolerance and metabolic physiology among redband trout populations in south-

541 eastern Oregon. J. Fish Biol. 64(2): 310-335. doi: 10.1111/j.0022-1112.2004.00292

542 Roughgarden, J. 1972. Evolution of niche width. Am. Nat. 106(952): 683-718.

543 doi:10.1086/282807.

544 Roy, M.L., Roy, A.G., Bergeron, N.E., and Fleming, I. 2013a. Individual variability in the 545 movement behaviour of juvenile Atlantic salmon. Can. J. Fish. Aquat. Sci. 70(2): 339-347. 546 doi:10.1139/cjfas-2012-0234.

547 Roy, M.L., Roy, A.G., and Bergeron, N.E. 2013b. Individual variability of wild juvenile Atlantic 548 salmon activity patterns: effect of flow stage, temperature, and habitat use. Can. J. Fish. Aquat. 549 Sci. 70(7): 1082-1091. doi:10.1139/cjfas-2012-0274.

550 Schlosser, I.J. 1991. Stream fish ecology: a landscape perspective. BioScience 41(10): 704-712. 551 doi:10.2307/1311765.

552 Sloat, M.R., Osterback, A.-M.K., and Magnan, P. 2013. Maximum stream temperature and the 553 occurrence, abundance, and behavior of steelhead trout (Oncorhynchus mykiss) in a southern 554 California stream. Can. J. Fish. Aquat. Sci. 70(1): 64-73. doi:10.1139/cjfas-2012-0228.

555 Steingrímsson, S.O., and Grant, J.W.A. 2003 Patterns and correlates of movement and site 556 fidelity in individually tagged young-of-the-year Atlantic salmon (Salmo salar). Can. J. Fish. 557 Aquat. Sci. 60(2):193-202. doi: 10.1139/f03-012 
558 Streicker, D.G., and Allgeier, J.E. 2016. Foraging choices of vampire bats in diverse landscapes: 559 potential implications for land-use change and disease transmission. J. Appl. Ecol. 53(4): 1280560 1288. doi:10.1111/1365-2664.12690.

561 Tinker, M.T., Bentall, G., and Estes, J.A. 2008. Food limitation leads to behavioral

562 diversification and dietary specialization in sea otters. Proc. Natl. Acad. Sci. USA 105(2): 560 563 565. doi:10.1073/pnas.0709263105.

564 U.S Environmental Protection Agency 2000. National Water Quality Inventory (EPA Publ. 841565 R-02-001). Washington, DC.

566 Van Horne, B. 1983. Density as a misleading indicator of habitat quality. J. Wildl. Manage. 567 47(4): 893-901. doi:10.2307/3808148.

568 Wathen, G., Weber, N., Bennett, S., Bouwes, N., and Jordan, C.E. 2017. An Assessment of the 569 Geographic Closure Assumption in Mark-Recapture Abundance Estimates of Anadromous 570 Steelhead Populations. North Am. J. Fish. Manage. 37(5): 951-961.

571 doi:10.1080/02755947.2017.1336132.

572 Weber, N., Bouwes, N., Pollock, M.M., Volk, C., Wheaton, J.M., Wathen, G., Wirtz, J., and 573 Jordan, C.E. (2017) Alteration of stream temperature by natural and artificial beaver dams. PLoS 574 ONE 12(5): e0176313. doi:10.1371/journal.pone.0176313

575 Wheaton, J.M., McHugh, P., Bouwes, N., Saunders, C., Bangen, S., Bailey, P., Nahorniak, M., 576 Wall, E., and Jordan, C.E. 2017. Upscaling site-scale ecohydraulic models to inform salmonid 577 population-level life cycle modelling and restoration actions - lessons from the Columbia River 578 Basin. Earth Surf. Processes and Landforms 43(1): 21-44. doi:10.1002/esp.4137. 
579 White, S.M., Giannico, G., and Li, H. 2014. A "behaviorscape" perspective on stream fish

580 ecology and conservation: linking fish behavior to riverscapes. WIREs Water 1(4): 385-400.

581 doi:10.1002/wat2.1033.

582 Wolf, M., and Weissing, F.J. 2012. Animal personalities: consequences for ecology and 583 evolution. Trends Ecol. Evol. 27(8): 452-461. doi:10.1016/j.tree.2012.05.001. 
585 Table 1. Descriptive information of beaver complex and run reaches, and the juvenile steelhead 586 that utilized respective study reaches. Individual residents reflect the number of fish observed in

587 two or more days, and detected at least 20 times.

\begin{tabular}{lccccccc}
\hline Study reach & Area $\left(\mathrm{m}^{2}\right)$ & Antennas & $\begin{array}{c}\text { Estimated density } \\
\text { (fish / meter) }\end{array}$ & $\begin{array}{c}\text { Proportion } \\
\text { tagged }(\%)\end{array}$ & $\begin{array}{c}\text { Avg. fork length } \\
\text { (range; } \mathrm{mm})\end{array}$ & $\begin{array}{c}\text { Individuals } \\
\text { detected }\end{array}$ & $\begin{array}{c}\text { Individual } \\
\text { residents }\end{array}$ \\
\hline Beaver complex & 89.3 & 11 & 3.2 & 36 & $111.0(80-190)$ & 96 & 65 \\
Run & 51.2 & 10 & 1.3 & 51 & $110.9(77-180)$ & 79 & 19 \\
\hline
\end{tabular}

588 
589 Table 2. Output from the generalized linear model that tested the importance of depth, velocity, 590 and study reach for microhabitat selection.

\begin{tabular}{lcccc}
\hline Variable & Estimate & Std. error & $\mathrm{T}$ - value & $p$ - value \\
\hline Interaction & 4.12 & 1.6 & 2.57 & 0.02 \\
Study Reach & 0.33 & 1.87 & 0.18 & 0.86 \\
Velocity & -23.89 & 10.76 & -2.22 & 0.04 \\
Depth & 47.53 & 12.16 & 3.91 & $<0.01$ \\
Reach * Velo. & 39.78 & 14.41 & 2.76 & 0.01 \\
Reach * Depth & -32.26 & 12.57 & -3.05 & 0.01 \\
\hline
\end{tabular}

591

Fig. 1. Maps displaying Bridge Creek's location the Pacific Northwest, USA (a); location of 593 study reaches within the Bridge Creek watershed (b); and the bathymetry and antenna locations 594 of the run (c) and beaver complex (d) reaches. The beaver dam in map (d) is indicated by the 595 brown, channel spanning obstruction. Antenna sizes and channel features in maps (c) and (d) are 596 all to scale. (Panels (a) and (b) are modified from map data provided by Oregon Spatial Data 597 Library, Salem, Oregon, USA).

Fig. 2. Scatterplots representing the depth (x-axis) and water velocity (y-axis) microhabitats present in each study reach. Here: "available" represents all the different microhabitats (equal to antenna area $\left.\left(0.44 \mathrm{~m}^{2}\right)\right)$ within each study reach; "sampled" represents the depths and velocities

602 at which our antennas were placed. The size of the open circles representing sampled locations 603 denotes the number of detections at each antenna.

Fig. 3. Row (a) depicts the average number of unique fish detected per day at each antenna within the two study reaches, during four diel periods. Diel periods are defined as: morning (6:00 
607

608

609

610

611

612

613

614

615

616

617

618

619

620

621

622

623

624

625

626

627

628

629

am-11:59 am), afternoon (12:00 pm - 5:59 pm), evening (6:00 pm - 11:59 pm), and night (12:00 am - 5:59 am). Rows (b) and (c) represent the average depths and water velocities, respectively, at each antenna calculated from water depth digital elevation models and hydraulic models.

Fig. 4. Bar charts ( $a$ and $b$ ) represent population-level changes in the rank of antenna preference by juvenile steelhead over four diel periods (average rank - rank at a given diel period) for beaver complex and run study reaches. A positive value indicates an antenna is more popular in the specified diel period compared to average popularity of the antenna. The histogram (c) depicts the frequency of coefficient of variation $(\mathrm{CV})$ of antenna preference rank within diel periods, whereby the larger the CV indicates greater changes between diel periods of antenna preference. T-test indicates a difference in means variation between the two study reaches, with a trend of increased $\mathrm{CV}$ can be noted in the beaver complex relative to the run.

Fig. 5. Kernel Density plots of the relative frequency of habitat use metrics for all individuals with the Beaver complex (B.Complex) and Run: Prop. Ant. Use = proportion of antennas used; PSi Activity = the degree of niche overlap (or specialization as measured by the PSi index) in terms of the amount of movement between and use of discrete antennas; and PSi Boldness = the degree of spatial overlap in terms of the relative distance individuals move between antennas. Statistical differences between study reaches are tested with T-tests (mean) and KS-test (spread). In all cases the distributions were compared with unequal samples sizes between the two study reaches (there are more fish in the Beaver complex), and with a bootstrapped approach to compare equal sample sizes - indicated as "bs". "NS" indicates the mean p-value of the comparisons that were greater than 0.1 . See methods for further details. 
631 Fig. 6. Kernel density plots of habitat use (proportion of antennas used) and specialization in 632 movement between and use of antennas (PSi Activity) for all individuals across the entire day 633 (far left plots) and broken into distinct diel periods. Statistical differences between study reaches 634 are tested with T-tests (mean) and KS-test (spread). In all cases the distributions were compared 635 with unequal samples sizes between the two study reaches (there are more fish in the Beaver 636 complex), and with a bootstrapped approach to compare equal sample sizes - indicated as "bs". 637 "NS" indicates the mean p-value of the comparisons that were greater than 0.1 . See methods for 638 further details. 


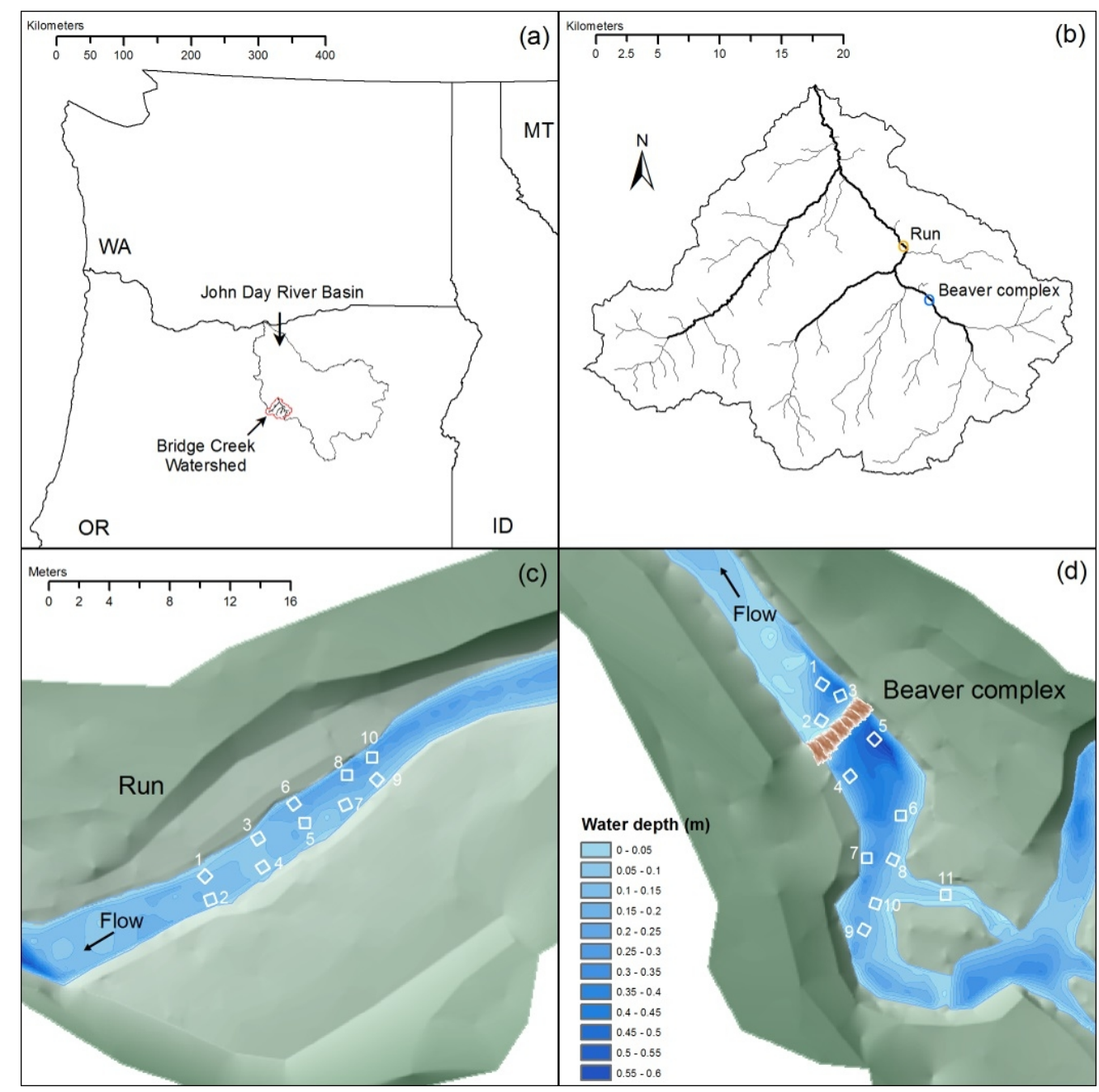

$185 \times 185 \mathrm{~mm}(144 \times 144 \mathrm{DPI})$ 


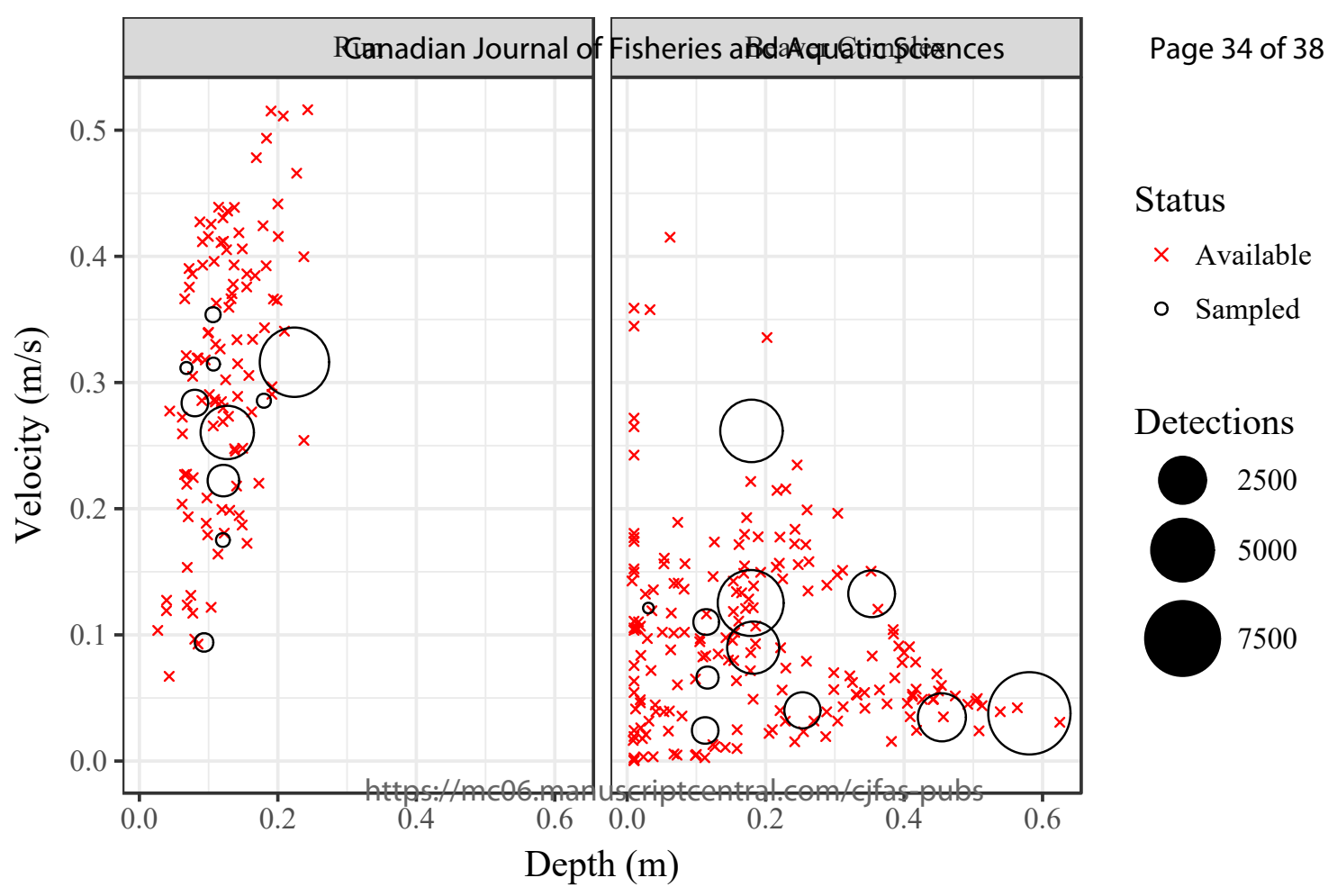




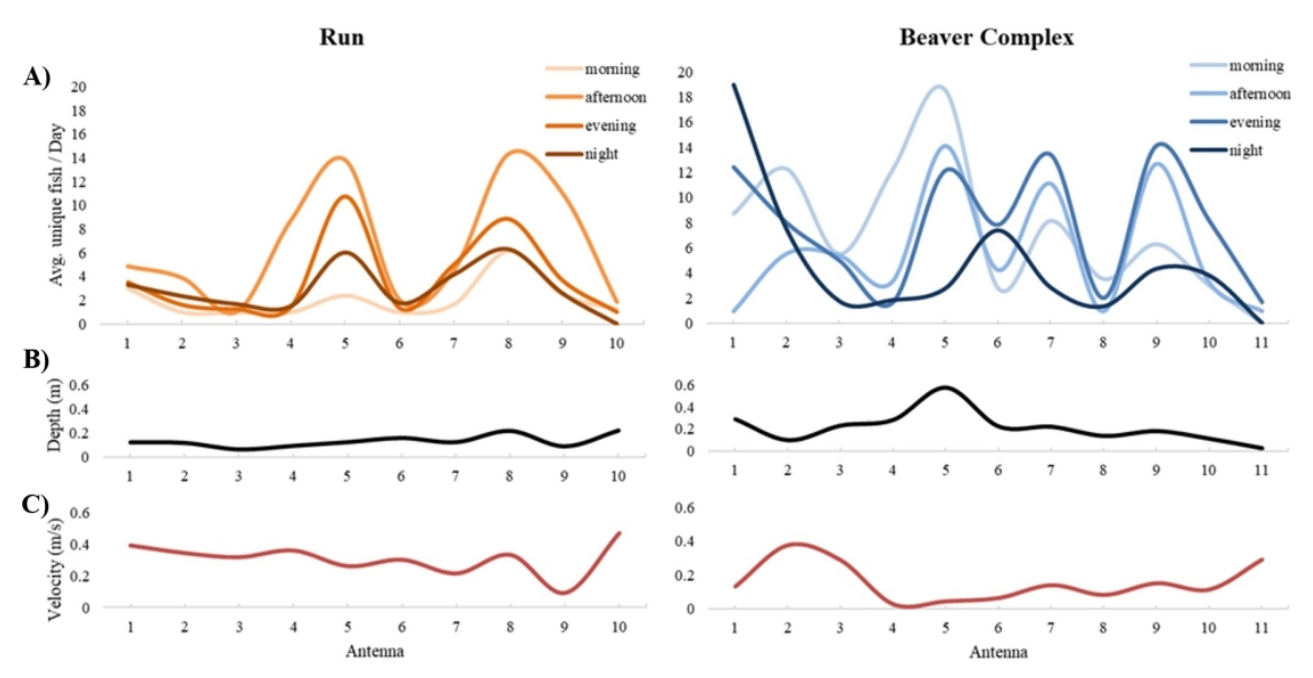

$322 \times 174 m m(144 \times 144$ DPI $)$ 

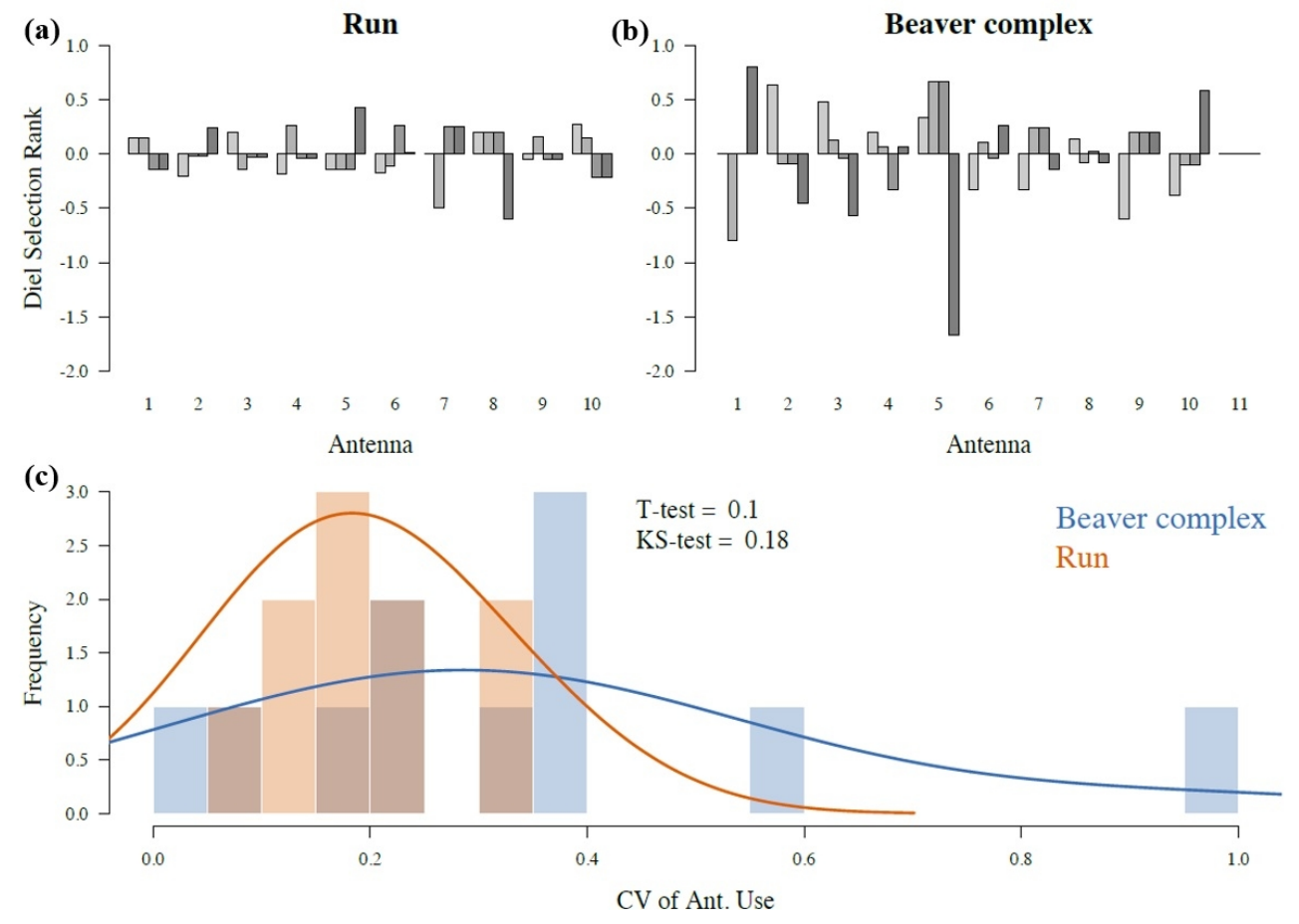

$211 \times 148 \mathrm{~mm}(144 \times 144 \mathrm{DPI})$ 
Page 37 of 38-test $=0.06 \mathrm{bs}=\mathrm{NS}$

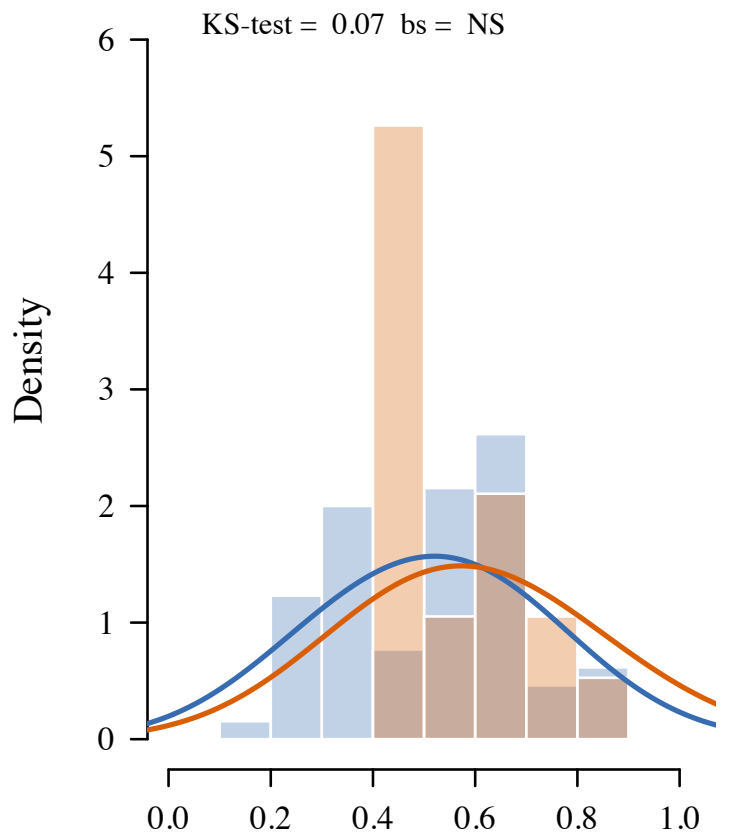

Prop. Ant. Use
Canadian Jpurnal gf Eisheriegs and Aquatic Sciences

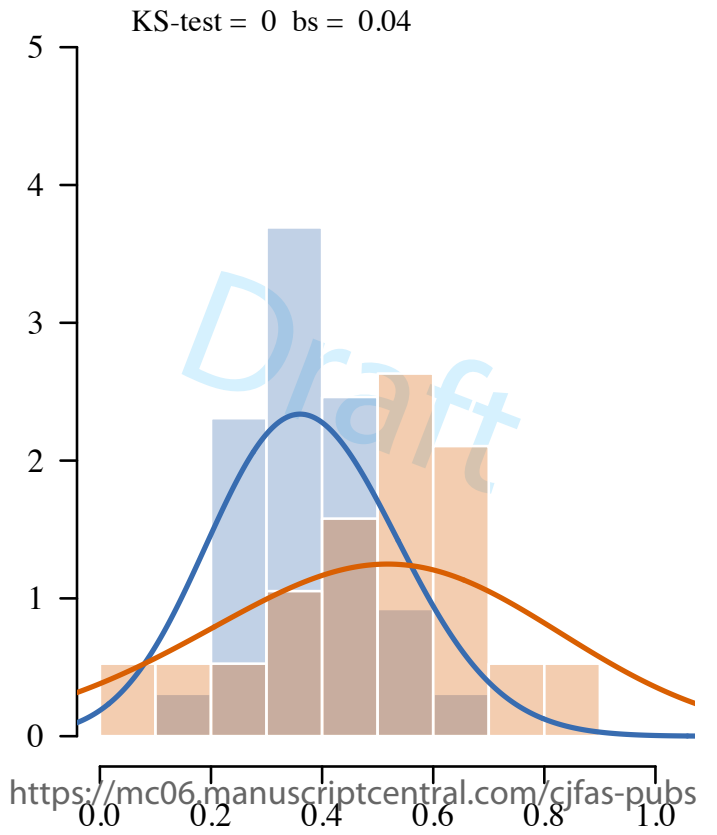

PSi Activity
T-test $=0$ bs $=0.01$

KS-test $=0.01$ bs $=0.07$

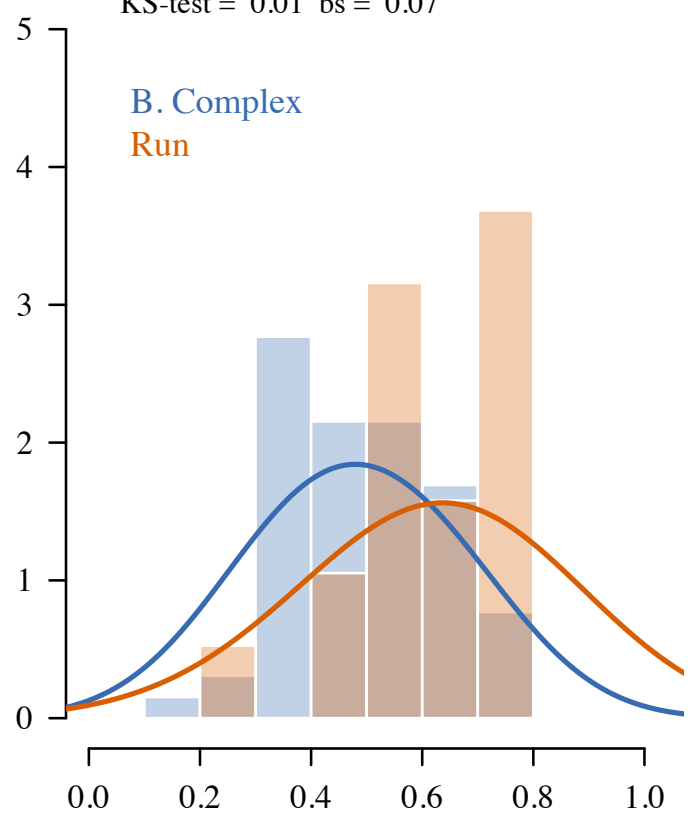

PSi Boldness 
